$$
\begin{array}{r}
\text { GA-A22828 } \\
\text { CONF-980374-- }
\end{array}
$$

\title{
A HELIUM-COOLED BLANKET DESIGN OF THE LOW ASPECT RATIO REACTOR RECEIVEO \\ by \\ OST
}

C.P.C. WONG, C.B. BAXI, R. CERBONE, E.T. CHENG, and E.E. REIS

Distaibution of this Document is unumat 4 MAsTER 
GA-A22828

\title{
A HELIUM-COOLED BLANKET DESIGN OF THE LOW ASPECT RATIO REACTOR
}

\author{
by \\ C.P.C. WONG, C.B. BAXI, R. CERBONE, ${ }^{*}$ \\ E.T. CHENG, ${ }^{*}$ and E.E. REIS
}

This is a preprint of a paper presented at the International Atomic Energy Agency Technical Committee Meeting on Fusion Power Plant Design, March 24-27, 1998, in Culham, United Kingdom and to be published in Fusion Engineering and Design.

"TSI Research, Solana Beach, California.

\author{
Work supported by \\ the U.S. Department of Energy under \\ Contract No. DE-AC03-98ER54411 and the SBIR Program
}

GA PROJECT 30007

MARCH 1998 


\section{ABSTRACT}

An aggressive low aspect ratio scoping fusion reactor design [1] indicated that a $2 \mathrm{GW}(\mathrm{e})$ reactor can have a major radius as small as $2.9 \mathrm{~m}$ resulting in a device with competitive cost of electricity at $49 \mathrm{mill} / \mathrm{kWh}$. One of the technology requirements of this design is a high performance high power density first wall and blanket system. A $15 \mathrm{MPa}$ helium-cooled, $\mathrm{V}$-alloy and stagnant $\mathrm{LiPb}$ breeder first wall and blanket design was utilized. Due to the low solubility of tritium in $\mathrm{LiPb}$, there is the concern of tritium migration and the formation of $\mathrm{V}$-hydride. To address these issues, a lithium breeder system with high solubility of tritium has been evaluated. Due to the reduction of blanket energy multiplication to 1.2 , to maintain a plant $Q$ of $>4$, the major radius of the reactor has to be increased to $3.05 \mathrm{~m}$. The inlet helium coolant temperature is raised to $436^{\circ} \mathrm{C}$ in order to meet the minimum V-alloy temperature limit everywhere in the first wall and blanket system. To enhance the first wall heat transfer, a swirl tape coolant channel design is used. The corresponding increase in friction factor is also taken into consideration. To reduce the coolant system pressure drop, the helium pressure is increased from 15 to $18 \mathrm{MPa}$. Thermal structural analysis is performed for a simple tube design. With an inside tube diameter of $1 \mathrm{~cm}$ and a wall thickness of $1.5 \mathrm{~mm}$, the lithium

breeder can remove an average heat flux and neutron wall loading of 2 and $8 \mathrm{MW} / \mathrm{m}^{2}$, respectively. This reference design can meet all the temperature and material structural design limits, as well as the coolant velocity limits. Maintaining an outlet coolant temperature of $650^{\circ} \mathrm{C}$, one can expect a gross closed cycle gas turbine thermal efficiency of $45 \%$. This study further supports the use of helium coolant for high power density reactor design. When used with the low aspect ratio reactor concept a competitive fusion reactor can be projected at $51.9 \mathrm{mill} / \mathrm{kWh}$. 


\section{INTRODUCTION}

An aggressive Low Aspect Ratio (LAR) scoping fusion reactor design [1] indicated that a $1998 \mathrm{MW}(\mathrm{e})$ reactor can have a major radius as small as $2.9 \mathrm{~m}$ resulting in a device with competitive cost of electricity at $49 \mathrm{mill} / \mathrm{kWh}$. This is an updated number about $3 \mathrm{mill} / \mathrm{kWh}$ lower than reported in Ref. [1] because of improvement in the calculation of the reactor economics. One of the technology requirements for this high power density reactor is a high performance first wall and blanket (FW/B) design to handle the peak surface heat flux and neutron wall loading of $2.73,11.1 \mathrm{MW} / \mathrm{m}^{2}$, respectively. A $15 \mathrm{MPa}$ helium-cooled, V-alloy and stagnant LiPb breeder (He-V-LiPb) FW/B design was utilized. The coolant inlet and outlet temperatures were $250^{\circ} \mathrm{C}$ and $650^{\circ} \mathrm{C}$, respectively. Due to the low solubility of tritium in $\mathrm{LiPb}$, there was the issue of high tritium partial pressure in the first wall and blanket system with the possible formation of V-hydride. This could lead to difficulties in controlling the migration of tritium and the possible weakening of the structural material. In addition, in order to avoid the issue of high ductile to brittle transition temperature of V-alloy under high neutron fluence, the recommended minimum V-alloy operating temperature has been increased to $400^{\circ} \mathrm{C}$ [2]. Therefore, since the V-alloy structure will be in thermal contact with the helium coolant, the helium inlet temperature of $250^{\circ} \mathrm{C}$ becomes an issue. To address these issues, a helium-cooled, V-alloy, lithium breeder (He-V-Li) FW/B system developed for the ARIES-DEMO design [3] was revisited to assess its capability of handling the high power density design. High solubility of tritium in lithium metal will mitigate the issue of tritium migration. To simplify the assessment, a simple bare tube with swirl tape heat transfer enhancement is used to address the key issue of removing high first wall surface heat flux with variation in tube wall thickness and diameter. Additional design 
adjustments are utilized to address some of the other key issues of the He-V-LiPb FW/B design. The performance impacts of the He-V-Li FW/B design to the low aspect ratio fusion reactor were also assessed by a scoping design code and the results are presented in this paper. 


\section{THE LOW ASPECT RATIO REACTOR DESIGN}

A scoping design code was prepared and utilized to evaluate the critical issues of the LAR design [1]. The physics basis for $A=1.4, \kappa=3, \beta_{\mathrm{T}}$ of $62 \%$, and bootstrap fraction of $87 \%$ equilibrium design point was derived from earlier work [4]. Using Krypton to enhance the radiation from the core, it was shown to be possible to reduce the divertor heat flux equal to that of the first wall. This feature comes with the corresponding reduction in plasma reactivity. This scoping code is used in the He-V-Li FW/B design to set the dimensions and geometry of the blanket module. For comparison, the design parameters of the He-V-LiPb and He-V-Li FW/B designs are presented in Table 1. For both designs, the goal is to have a plant $\mathrm{Q}$ (gross power/recirculating power) to be $\geq 4$. Schematic of the LAR design is shown in Fig. 1. As indicated, no divertor module would be necessary if the approach of impurity core radiation to distribute the transport power could be demonstrated by LAR experiments.

The key differences between the $\mathrm{LiPb}$ and $\mathrm{Li}$ breeder designs are as follows. Neutronics results show that the change in blanket energy multiplication from the $\mathrm{LiPb}$ to $\mathrm{Li}$ breeder design is from 1.4 to 1.2 . In order to maintain the plant $\mathrm{Q} \geq 4$, the reactor size has to be increased as shown in Table 1. Furthermore, to compensate for the low volumetric tritium breeding capability of the Li blanket, the outboard total FW/B and plenum thickness is increased from $1.0 \mathrm{~m}$ to $1.2 \mathrm{~m}$. These changes also contribute to the increase dimension of the TF-coil, and impact the economic of the reactor as presented in Section 7. The other difference as shown in Table 1, is the use of higher concentration of $\mathrm{Kr}$ as core radiation material and thus allowing the divertor heat flux to be closer to that of the first wall heat flux. 
Table 1

Key Physics and Engineering Parameters of two LAR FW/B Designs

\begin{tabular}{|c|c|c|}
\hline & $\mathrm{He}-\mathrm{V}$-LiPb Design & He-V-Li Design \\
\hline \multicolumn{3}{|l|}{ Reactor geometry: } \\
\hline Plasma aspect ratio, $\mathrm{A}$ & 1.4 & 1.4 \\
\hline Plasma vertical elongation, & 3.0 & 3.0 \\
\hline Minor plasma radius, a, (m) & 2.08 & 2.175 \\
\hline Major toroidal radius, $\mathrm{R}_{\mathrm{O}},(\mathrm{m})$ & 2.9 & 3.045 \\
\hline Plasma volume, $\left(\mathrm{m}^{3}\right)$ & 740.7 & 853.0 \\
\hline \multicolumn{3}{|l|}{ First wall/blanket geometry: } \\
\hline First-wall surface area $\left(\mathrm{m}^{2}\right)$ & 493.3 & 542.0 \\
\hline Number of blanket module & 24 & 36 \\
\hline Module width at midplane $(\mathrm{m})$ & 1.3 & 0.91 \\
\hline Module poloidal length (m) & 14.6 & 15.2 \\
\hline Module outboard radial depth (m) & 1.0 & 1.2 \\
\hline \multicolumn{3}{|l|}{ Plasma parameters: } \\
\hline Toroidal beta $(\%)$ volume averaged & 62 & 62 \\
\hline Poloidal beta $(\%)$ volume averaged & 1.43 & 1.43 \\
\hline On-axis toroidal field $(\mathrm{T})$ & 2.17 & 2.15 \\
\hline Plasma current (MA) & 31.5 & 32.8 \\
\hline Plasma ion temperature $(\mathrm{keV})$ peak & 25 & 25 \\
\hline Plasma electron density, $\mathrm{n}_{\mathrm{e}},\left(10^{20} / \mathrm{m}^{3}\right)$ & 2.38 & 2.36 \\
\hline Plasma ion density $\left(10^{20} / \mathrm{m}^{3}\right)$ peak & 1.74 & 1.69 \\
\hline Energy confinement time $\left(\tau_{\mathrm{E}}, \mathrm{s}\right)^{*}$ & 1.3 & 1.5 \\
\hline Helium concentration & 0.1 & 0.1 \\
\hline $\mathrm{Kr}$ concentration, fraction of $\mathrm{n}_{\mathrm{e}}$ & 0.0019 & 0.0023 \\
\hline Effective plasma charge $\left(\mathrm{Z}_{\mathrm{eff}}\right)$ & 3.59 & 4.12 \\
\hline Average plasma power density $\left(\mathrm{MW} / \mathrm{m}^{3}\right)$ & 6.6 & 6.25 \\
\hline Fusion power (MW) & 4909 & 5333 \\
\hline \multicolumn{3}{|l|}{ Toroidal field coil summary: } \\
\hline Number of TF coils & 12 & 12 \\
\hline Mass of TF coil set (tonne) & 1193 & 1407 \\
\hline TF-coil current per coil (MA) & 2.8 & 2.7 \\
\hline TF central column avg. current density $\left(\mathrm{MA} / \mathrm{m}^{2}\right)$ & 18 & 17.4 \\
\hline TF coil resistive power consumption, $[\mathrm{MW}(\mathrm{e})]$ & 270.9 & 278.4 \\
\hline \multicolumn{3}{|l|}{ Engineering summary: } \\
\hline Fusion power $(\mathrm{MW})$ & 4909 & 5333 \\
\hline Total useful thermal power (MW) & 5833 & 5604 \\
\hline Average first wall heat flux $\left(\mathrm{MW} / \mathrm{m}^{2}\right)$ & 1.95 & 2.1 \\
\hline Max. divertor heat flux $\left(\mathrm{MW} / \mathrm{m}^{2}\right)$ & 9.3 & 2.13 \\
\hline $\mathrm{CD} /$ heater $\left(\mathrm{FWCD}^{\dagger}\right)$ power, $(\mathrm{MW})$ & 58 & 67.2 \\
\hline Plant Q & 4.2 & 4.0 \\
\hline Gross electrical output power $[\mathrm{MW}(\mathrm{e})]$ & 2625 & 2622 \\
\hline Thermal conversion efficiency, CCGT (\%) & 45 & 45 \\
\hline Net electrical output power [MW(e)] & 1998 & 1966 \\
\hline
\end{tabular}

${ }^{*} \tau_{\mathrm{E}}$ defined as plasma energy divided by heating power $\left(\mathrm{P}+\mathrm{P}_{\mathrm{fwcd}}\right)$.

†Fast wave Current Drive 


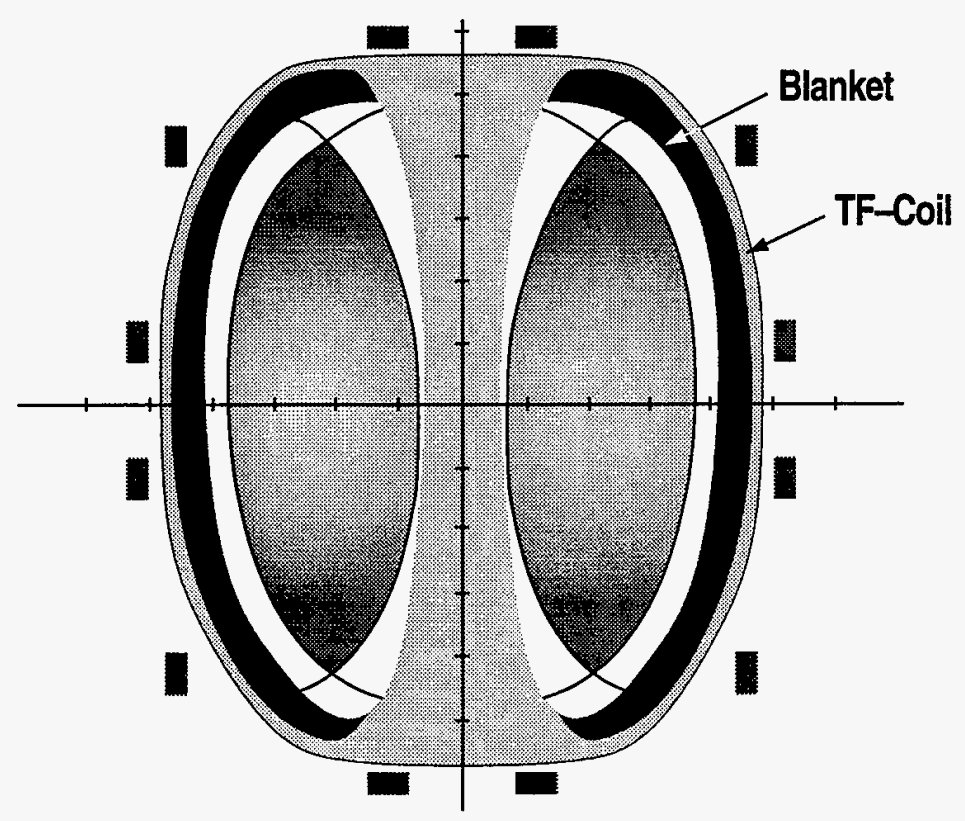

Fig. 1. LAR power plant core. 


\section{THE HE-LI-V FW/B CONFIGURATION}

With the goal of designing to high surface heat flux and neutron wall loading, the combination of helium cooling, V-alloy as the structural material and the use of Li as the tritium breeder has been re-assessed. The same nested shell configuration was selected as shown in Fig. 2. The blanket module consists of U-shape tube shells connected to the coolant plenum and structural support located at the back of the blanket. The first wall is a shell separated from the module box containing the blanket coolant shells and the molten breeder. As shown, the tube shells can be fabricated by imbedding coolant tubes in V-alloy sheets by various means like diffusive bonding. On top of the V-alloy tube facing the plasma, a thin coating of erosion resistant material like $1 \mathrm{~mm}$ thick $\mathrm{W}$ may be needed, but this is not included in the following thermal/structrural analysis. Between the blanket cooling shells the module is filled with molten lithium maintained at atmospheric pressure connected to a common channel and then to the free surface of each poloidal sector. The coolant is routed from the back poloidal plenum to cool the first wall and then re-routed to cool the rest of the blanket. This routing scheme is selected to minimize the first wall coolant temperature and to optimize the blanket coolant outlet temperature for high thermal conversion efficiency. Table 2 shows the design input parameters of the He-Li-V FW/B design. To match the coolant condition of the closed cycle gas turbine system design [3], the inlet helium coolant temperature is increased to $436^{\circ} \mathrm{C}$. This will also meet the required minimum V-alloy operating temperature of $400^{\circ} \mathrm{C}$. To enhance the heat removal capability of the helium-cooled first wall, a swirl tape insert coolant channel design is used with correspondingly increase coolant flow friction factor. In order to avoid excessive first wall pressure drop and pumping power, the helium pressure 
is increased to $18 \mathrm{MPa}$. Details of the thermal structural analysis are presented in the next section.

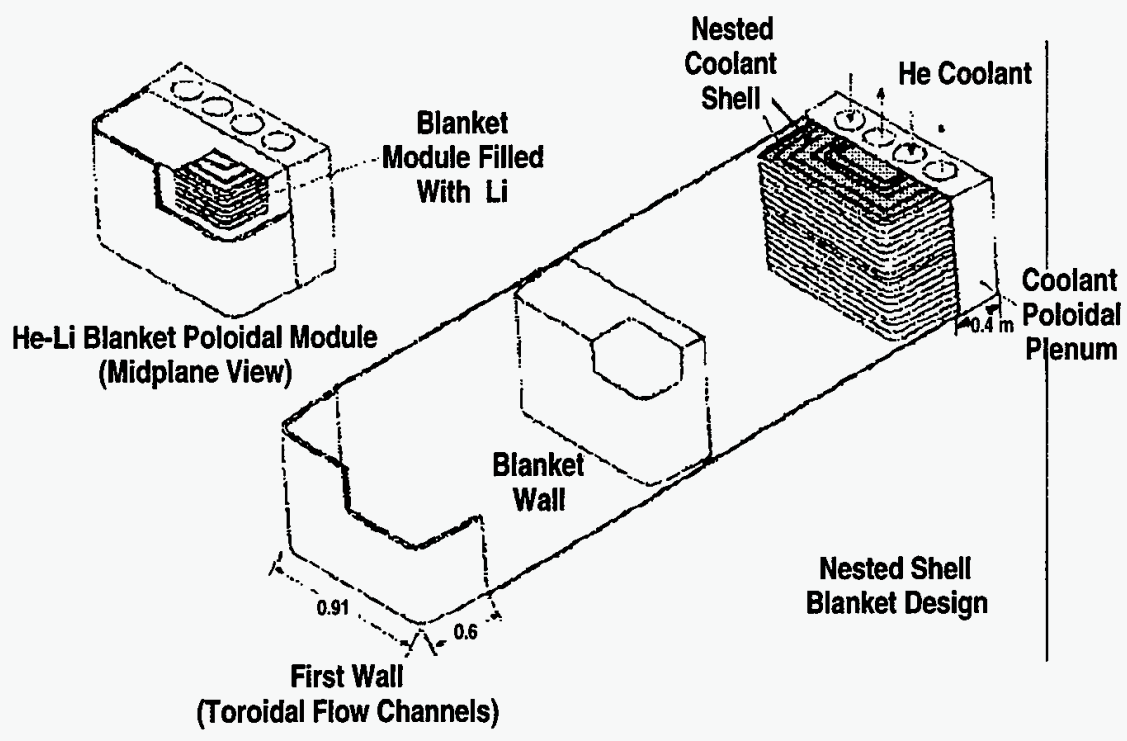

Fig. 2. Nested shell blanket design.

Table 2

He-Li-V FW/B Design Input Parameters

Thermal power per module, MW

Average surface heat flux, $\mathrm{MW} / \mathrm{m}^{2}$

Average neutron wall loading, $\mathrm{MW} / \mathrm{m}^{2}$

Surface loading peaking factor

Neutron wall loading peaking factor

Structural material

Tritium breeder

Helium pressure, MPa

Inlet helium temperature, ${ }^{\circ} \mathrm{C}$

Outlet helium temperature, ${ }^{\circ} \mathrm{C}$
149

2.0

7.87

1.4

1.4

V-alloy

$\mathrm{Li}$

18

436

650 


\section{THERMAL STRUCTURAL DESIGN ANALYSIS}

The critical element of the LAR FW/B design is the first wall. As shown in Table 2, at a peaking factor of 1.4 located at the midplane, the maximum first wall surface heat flux can be as high as $2.8 \mathrm{MW} / \mathrm{m}^{2}$. A simple first wall tube oriented in the toroidal direction across the blanket module is used for the thermal structural analysis. Volumetric power generations for $\mathrm{V}$-alloy and lithium are results generated from neutronics calculations. Fraction of power removed by the first wall can then be determined. Along with the FW/B coolant inlet and outlet temperatures, the first wall helium outlet temperature can be determined. Effects of coolant property change as a function of temperature are included in the analysis. Parametric heat transfer coefficient and corresponding friction factor for the internal swirl tape is used for the temperature calculation at the inlet, middle and outlet locations of the first wall tube. In parallel, primary and secondary stress of the first wall was estimated by the model of a circular tube. This procedure is used to determine the design window of wall thickness and tube diameter of the first wall tube as a function of power input. The input power consists of the volumetric power generation from neutrons and the corresponding surface heat flux from radiation.

Input design parameters are presented in Table 1. The design limits and criteria for $\mathrm{V}$-alloy used for the analysis are given in Table 3.

To enhance the heat removal capability of the coolant, swirl tape insert is used. The swirl tape tube design also helps to mitigate the uncertainty from the one sided heating of the first wall. 
Table 3

Design Limits and Criteria for the He-V-Li FW/B Design

Minimum V-alloy temperature $\left({ }^{\circ} \mathrm{C}\right) \quad \geq 400$

Maximum V-alloy temperature $\left({ }^{\circ} \mathrm{C}\right) \quad \leq 700$

Primary stress limit, Sm (MPa) $\quad<120$

Total stress $=$ primary + secondary, $3 \mathrm{Sm}(\mathrm{MPa})[5] \quad<360$

Li breeder maximum temperature $\left({ }^{\circ} \mathrm{C}\right) \quad<1000$

Coolant velocity design limits:

Vibration limits $(\mathrm{m} / \mathrm{s})[6] \quad<1289$

Sonic speed $(\mathrm{m} / \mathrm{s})$ at $462^{\circ} \mathrm{C} \quad<725$

Pressure drop: $\mathrm{P}_{\mathrm{fw}} / \mathrm{P} \quad<5 \%$ for CCGT

FW PP/Module $\quad \mathrm{P}_{\text {th }}<5 \%$

The hydraulic diameter for the swirl tape tube is given by,

$$
R_{\text {hy }}=\left(\pi \cdot r_{\text {tube }}^{2}-2 \cdot x_{\text {tape }} \cdot r_{\text {tube }}\right) /\left(2 \cdot \pi \cdot r_{\text {tube }}+4 \cdot r_{\text {tube }}\right)
$$

Where $r_{\text {tube }}$ is the cooling tube inside radius, $x_{\text {tape }}$ is the swirl tape thickness.

The heat transfer enhancement factor is given by:

$$
\mathrm{E}_{\mathrm{h}}=2.18 / \mathrm{Y}^{0.09} \text {, }
$$

and the enhanced friction factor is given by,

$$
E_{f}=2.2 / Y^{0.406}
$$


Where $\mathrm{Y}$ is the twist ratio, defined as twice the ratio of the helical pitch to diameter, usually has the value in the range of 2 to 3 . For our study, we pick $Y=2$.

Based on the above definitions, typical helium-cooled Nusselt number and heat transfer coefficient for the swirl tape design can be calculated. 


\section{THERMAL STRUCTURAL DESIGN RESULTS}

Among the design criteria given above, for most of the cases that we considered, the maximum $\mathrm{V}$-alloy temperature is the key constraint. By designing to the maximum tube temperature of $700^{\circ} \mathrm{C}$, Fig. 3 shows the first wall tube wall thickness as a function of the maximum neutron wall loading for different tube diameters. For a given tube diameter, the allowable tube wall thickness decreases as the maximum neutron wall loading increases. All the tubes with diameter between 0.6 to $1.0 \mathrm{~cm}$ can satisfy both structural design criteria up to a maximum neutron wall loading of $12.6 \mathrm{MW} / \mathrm{m}^{2}$. For the $1.6 \mathrm{~cm}$ diameter tube, the primary stress would be exceeded at a maximum neutron wall loading higher than $9 \mathrm{MW} / \mathrm{m}^{2}$ at a wall thickness of $1.2 \mathrm{~mm}$, as shown by the doted line. Figure 4 shows for tube diameters less than $1 \mathrm{~cm}$, the fraction of power required for pumping the helium through the first wall can be excessive for this design. To meet all the design criteria, the $1 \mathrm{~cm}$ diameter tube with $1.5 \mathrm{~mm}$ thick wall shows a neutron wall loading heat flux handling capability of $11.2 \mathrm{MW} / \mathrm{m}^{2}$ and is selected as the reference design for further evaluation. The maximum coolant velocity at $150 \mathrm{~m} / \mathrm{s}$ is well below the sonic and critical velocity limits to cause vibration of the coolant channel. The corresponding first wall pumping power fraction is $4 \%$. Design parameters and thermal structural results of the reference design are given in Table 4. It should be noted as in Fig. 3, in term of heat transfer performance the limiting parameter is the heat flux impinging the first wall, which in this case is about $1 / 4$ of the neutron wall loading for this reference design of high core radiation. Neutron wall loading is a good measure of the high power density blanket performance. 


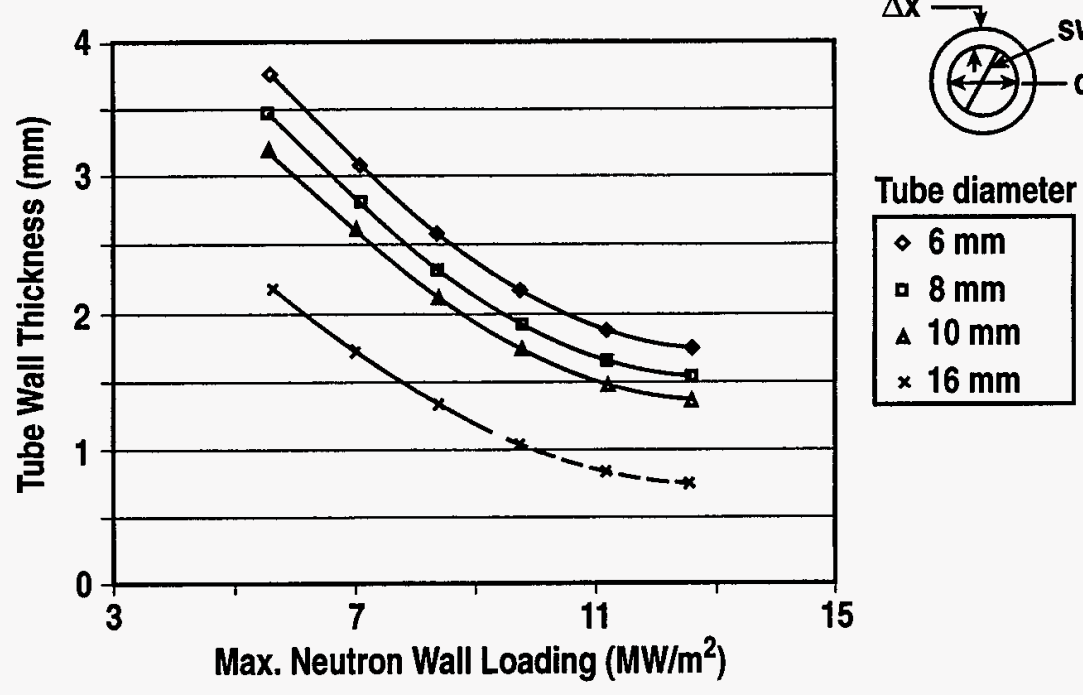

Fig. 3. Tube wall thickness, $V$-alloy $T_{\max }$ at $700^{\circ} \mathrm{C}$. (Corresponding heat flux is about $1 / 4$ of neutron wall loading.)

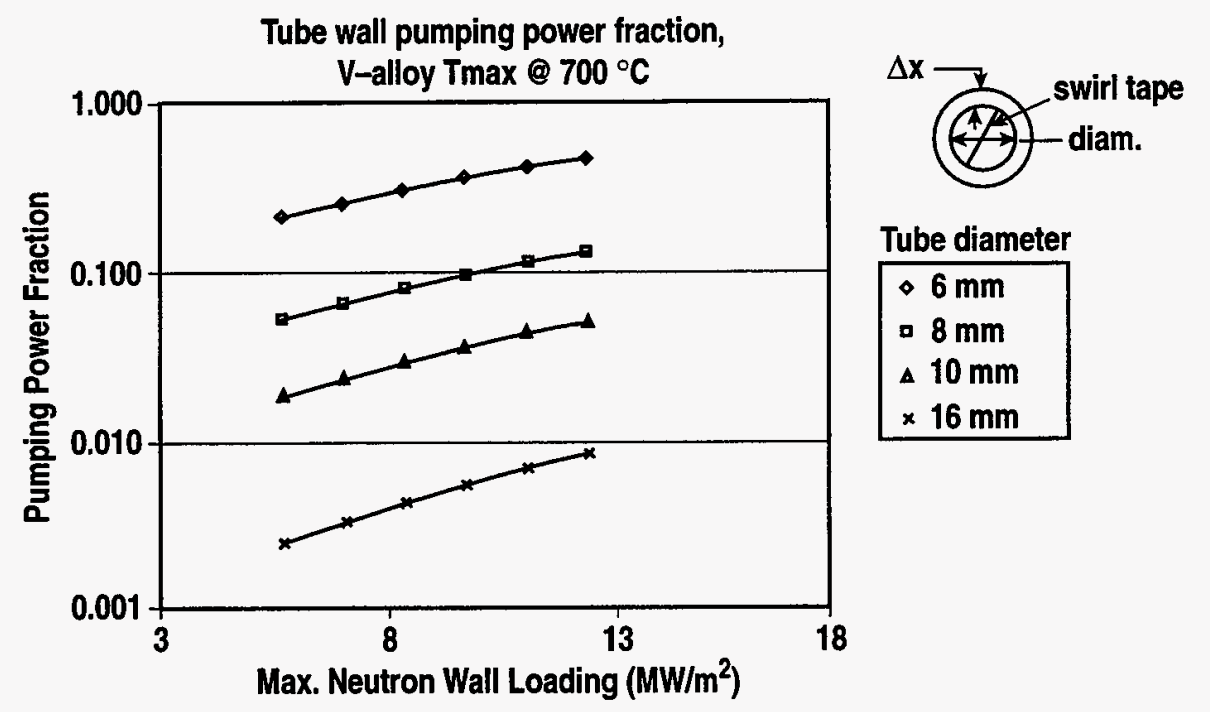

Fig. 4. First wall pumping power fraction, $V$-alloy $\mathrm{T}_{\max }$ at $700^{\circ} \mathrm{C}$. (Corresponding heat flux is about $1 / 4$ of neutron wall loading.) 


\section{Table 4}

\section{Reference FW/B design parameters}

First wall parameters:

Tube diameter $(\mathrm{cm})$

Tube wall thickness ( $\mathrm{mm}$ )

1

Heat transfer enhancement

1.5

Tape thickness (mm)

swirl tape

Maximum heat transfer coefficient, $\mathrm{h}\left(\mathrm{W} / \mathrm{m}^{2}{ }^{\circ} \mathrm{C}\right)$

1

Maximum V-alloy temperature $\left({ }^{\circ} \mathrm{C}\right)$

$4.34 \times 10^{4}$

Maximum Li and V-alloy interface temp $\left({ }^{\circ} \mathrm{C}\right)$

697

554.8

First wall primary stress (MPa)

60

First wall total stress (primary + secondary) (MPa)

195

First wall pressure drop (MPa)

0.5

First wall delP/P

0.03

First wall pumping power (MW)

6.3

Pump power fraction

0.042

Blanket parameters:

Blanket cooling shell separation $(\mathrm{cm}) \quad 3.6$

$\begin{array}{ll}\text { Radial blanket thickness (m) } & 0.8\end{array}$

Blanket tube diameter $(\mathrm{cm}) \quad 1$

Blanket tube wall thickness (mm) $\quad 1.5$

Blanket materials volume fractions:
Helium
0.236
V-alloy
0.14
$\mathrm{Li}$
0.624

Power conversion:

Gross direct cycle gas turbine thermal efficiency $\quad 45 \%$ 


\section{NEUTRONICS PERFORMANCE}

A major-radius model [1] calculation was performed for the He-V-Li option. The material volume fractions were determined after design iterations between the configurational design, scoping thermal-hydraulics and neutronics calculations. Radial volumetric power deposition is used to determine the necessary separation between blanket cooling shells, while maintaining the maximum temperature of the cooling tube to be less than $700^{\circ} \mathrm{C}$. The blanket first $\mathrm{Li}$ layer is $2.1 \mathrm{~cm}$ thick and the others are $3.6 \mathrm{~cm}$ thick resulting in over all material fractions of $\mathrm{He}, \mathrm{V}$-alloy and $\mathrm{Li}$ to be $0.236,0.14$ and 0.624 , respectively. Similar V-alloy, lithium breeder self-cooled blanket design has projected adequate tritium breeding [7,8]. The addition of helium in blanket will not impact tritium breeding but will increase the outboard blanket by $20 \%$ to $25 \%$. Furthermore, with the approach of core radiation, additional cooling structural at the divertor to remove peaking surface heat flux of $>5 \mathrm{MW} / \mathrm{m}^{2}$ may not be required. This would have positive contribution to tritium breeding by allowing larger blanket surface coverage including the traditionally divertor areas. The additional advantage of the Libreeder blanket over the $\mathrm{LiPb}$ blanket is eliminating the need for the continuous extraction of $\mathrm{Bi}[9]$, generated from $\mathrm{Pb}$, a precursor for the formation of the potentially hazardous isotope ${ }^{210} \mathrm{Po}$ 


\section{MATERIALS COMPATIBILITY}

$\mathrm{He} / \mathrm{V}$-alloy compatibility issues [1] will have to be resolved. Possible approach is by coolant cleanup, coating (e.g. aluminized layer [9] ) or bi-metallic tube [10] (e.g. 10 to 50 bonded FS layer between the He and V-alloy interface). 


\section{ECONOMICS IMPLICATIONS}

A costing estimate of the He-V-Li blanket LAR reactor was performed. Results are

presented in Table 5. Including change out costs, replacement of the first $25 \mathrm{~cm}$ of the central column 14 times, and the FW/B modules 17 times, during the 30 years plant life at $75 \%$ availability, the reference design has at COE of $51.9 \mathrm{mill} / \mathrm{kWh}$. This is higher than the $\mathrm{He}-\mathrm{V}-\mathrm{LiPb}$ result of 49 mill/kWh. The differences between the two designs are lower blanket multiplication of the Li blanket, and the use of higher concentration of $\mathrm{Kr}$ for core radiation. The latter will lead to lower fusion reactivity. These effects lead to a larger machine at similar power output. Further more, by matching closer to the coolant inlet and outlet temperature of the CCGT operation, the smaller inlet and outlet temperature differential also leads to higher coolant pumping power. 
Table 5

Costing of He-V-Li Blanket LAR Reactor Design

\begin{tabular}{|c|c|c|}
\hline Account No. & Account Title & \$M (1992) \\
\hline 20. & Land and land rights & 10.4 \\
\hline 21. & Structures and site facilities & 535.6 \\
\hline 22. & Reactor plant equipment & 1199.0 \\
\hline 22.1.1 & FW/blanket/reflector & 126.9 \\
\hline 22.1.2 & Shield & 39.6 \\
\hline 22.1.3 & Magnets & 100.6 \\
\hline 22.1.4 & Supplemental-heating/CD systems & 123.5 \\
\hline 22.1.5 & Primary structure and support & 114.4 \\
\hline 22.1.6 & Reactor vacuum systems & 99 \\
\hline 22.1.7 & Power supply, switching and energy storage & 134.2 \\
\hline 22.1.8 & Impurity control & 16.7 \\
\hline 22.1 .9 & Direct energy conversion system & 0.0 \\
\hline 22.1 .10 & ECRH breakdown system & 4.3 \\
\hline 22.1 & Reactor equipment & 739.3 \\
\hline 22.2 & Main heat transfer and transport systems & 440. \\
\hline 23. & Turbine plant equipment & 484.6 \\
\hline 24. & Electric plant equipment & 159.3 \\
\hline 25. & Miscellaneous plant equipment & 87.7 \\
\hline 26. & Special materials & 57.8 \\
\hline 90. & Direct cost (not including contingency) & 2524 \\
\hline 91. & Construction services and equip. & 320.9 \\
\hline 92. & Home office engineering and services & 126.2 \\
\hline 93. & Field office engineering and services & 151.5 \\
\hline 94. & Owner's cost & 465.7 \\
\hline 96. & Project contingency & 621. \\
\hline 97. & Interest during construction (IDC) & 692.4 \\
\hline \multirow[t]{7}{*}{99.} & Total cost $\left(\$ 10^{6}\right)$ & 4884 \\
\hline & Unit overnight cost $[\$ / \mathrm{kW}(\mathrm{e})]$ & 4192 \\
\hline & Capital return $[\mathrm{mill} / \mathrm{kW}(\mathrm{e}) \mathrm{h}]$ & 36.74 \\
\hline & Plant availability & 0.75 \\
\hline & Decommissioning [mill/kW(e)] & 0.5 \\
\hline & Fuel [mill/kW(e)h] & 0.03 \\
\hline & $\mathrm{LSA}^{*}=2$ total COE${ }^{\dagger}[\mathrm{mill} / \mathrm{kW}(\mathrm{e}) \mathrm{h}]$ & 51.9 at $\eta_{\text {th }}=45 \%$ \\
\hline
\end{tabular}

* Level of safety assurance (16); account numbers from ARIES system code.

$\uparrow \mathrm{COE}$ includes replacement costs. 


\section{CONCLUSIONS}

This paper shows that the He-V-Li FW/B LAR reactor, based on similar aggressive design approach in physics and technology as the He-V-LiPb FW/B LAR design can also become a low activation economical fusion energy system. Some of the critical issues related to the $\mathrm{LiPb}$ breeder design can be resolved by using $\mathrm{Li}$ as the breeder. Based on the given geometry, thermal-structural analysis of a single tube of $1 \mathrm{~cm}$ in diameter and a wall thickness of $1.5 \mathrm{~mm}$ shows the potential of handling an average neutron wall loading of $8 \mathrm{MW} / \mathrm{m}^{2}$ and the corresponding maximum surface heat flux of $2.76 \mathrm{MW} / \mathrm{m}^{2}$. The primary design limitation is the maximum temperature of the first wall, which is contributed mainly by the maximum heat flux for the case of enhanced core radiation. The swirl tape heat transfer enhancement has to be used. To match the coolant condition of the CCGT, the inlet coolant temperature is raised to $436^{\circ} \mathrm{C}$ while maintaining the coolant outlet temperature of $650^{\circ} \mathrm{C}$. But in order to control the required coolant pumping power to an acceptable level, the coolant pressure has to be raised to $18 \mathrm{MPa}$. Advantages of the $\mathrm{Li}$ breeder over the $\mathrm{LiPb}$ breeder design are better control of the bred tritium because of the higher solubility of tritium in lithium, and less chemistry control than the $\mathrm{LiPb}$ option, since there is no generation of $\mathrm{Bi}$ with the $\mathrm{Li}$ breeder design. The key relative disadvantage of the Li breeder design, when applied to the water-cooled central column LAR design is the higher reactivity of Li when mixed with water. This event will have to be avoided by design. The present design has five physical barriers between the Li breeder and the LAR central column water coolant. Impacts of the lower blanket energy multiplication of the Li breeder design are not significant, it increases the COE from 49 mill/kWhr for the LiPb breeder to 51.9 mill/kWhr for the Li breeder design. The results of this study further support the high power density fusion reactor 
development path by making use of the LAR approach. At the same time the effort in developing the high power density helium-cooled first wall blanket system should be increased and evolved the concept to a robust design with high reliability. Special attention should be given to the method of fabrication and the joining of coolant channels to the plenum. It should also be pointed out that this He-V-Li FW/B system can also be applied to other high power density confinement concepts. 


\section{REFERENCES}

[1] C.P.C. Wong, R. Cerbone, E. T. Cheng, R. L. Miller, R. D. Stambaugh, "The Low Aspect Ratio Design Concept-Possibility of an Acceptable Fusion Power System," Proc. of 17th IEEE/NPSS Symp on Fusion Engineering, October, 1997, San Diego, to be published.

[2] S.J. Zinkle, ORNL, personal communication, January 1998.

[3] C.P.C. Wong, et al., "Evaluation of U.S. DEMO Helium-Cooled Blanket Options," Proc. of 16th IEEE/NPSS Symp. on Fusion Engineering, Champaign, Illinois, 1995 (Institute of Electrical and Electronics Engineers, Inc., Piscataway, New Jersey, 1996) Vol. II, p. 1145.

[4] R.D. Stambaugh, V.S. Chan, R.L. Miller, and M.J. Schaffer, Fusion Technol. 33, 1 (1998).

[5] F. Najmabadi, et al., "The Starlite Study: Assessment of Options for Tokamak Power Plants," Final Report, University of California, San Diego Report UCSDENG-005 (1997).

[6] R.D. Blevins, "Flow-Induced Vibration, 2nd Edition," Van Norstrand Reinhold Press, 1990.

[7] L.A. El-Guebaly, et al., "Neutronics Aspects of ARIES-II and ARIES-IV Fusion Power Reactors," Fusion Technol. 21, 2128 (1992).

[8] S. Malang, et al., "Development of Self-Cooled Liquid Metal Breeder Blankets," FKG Technical Report FZKA 5581, November 1995.

[9] K. Natesan and W.K. Soppet, "Tensile Properties of Aluminized V-5Cr-5Ti Alloy After Exposure in Air Environment," Fusion Materials, Semi-Annual Progress Report for Period Ending June 30, 1997, p. 50.

[10] W.R. Johnson, General Atomics, personal communication, 1998. 


\section{ACKNOWLEDGMENT}

This is a report of work supported by TSI Research Inc. funded under Department of

Energy SBIR program and the U.S. Department of Energy under Contract No. DE-AC0398ER54411. 

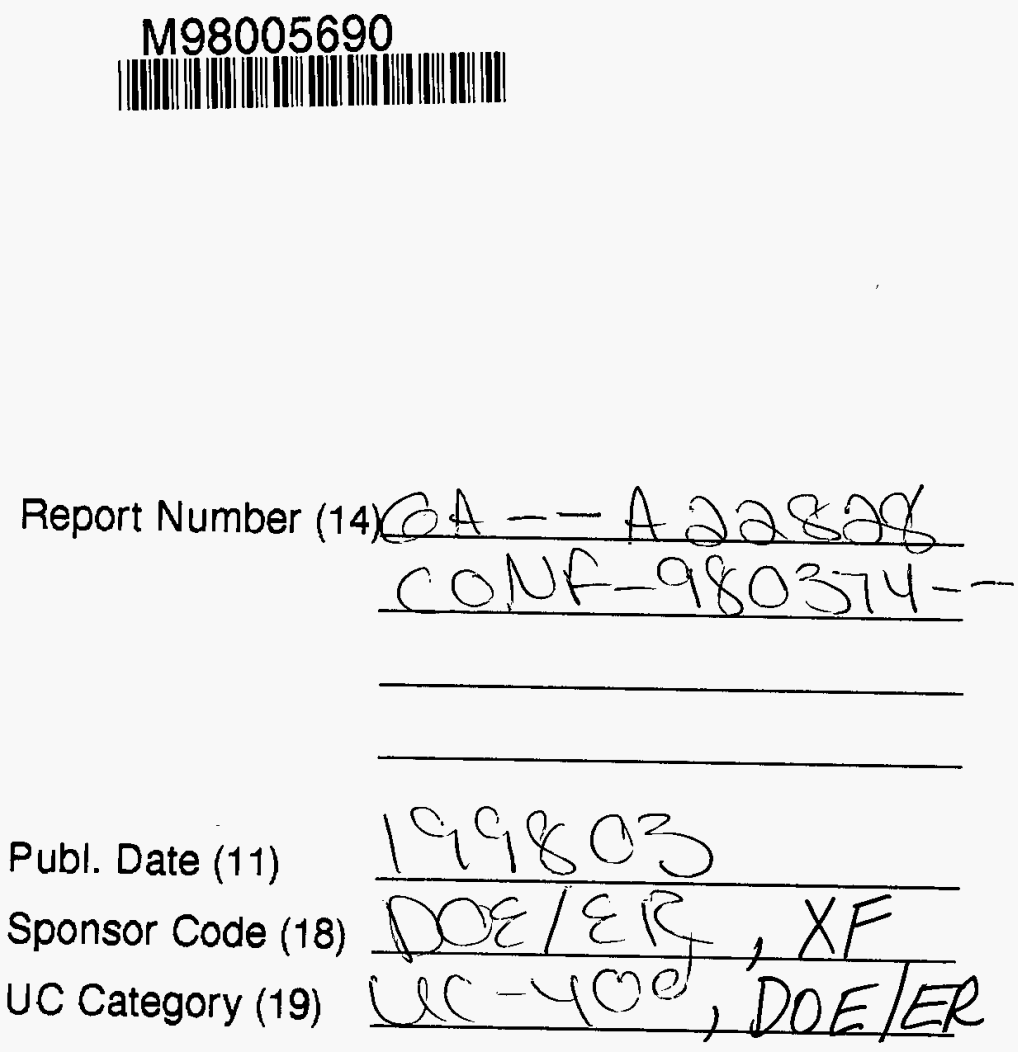

\section{1}

DITC QUATITY INOPECTED 1

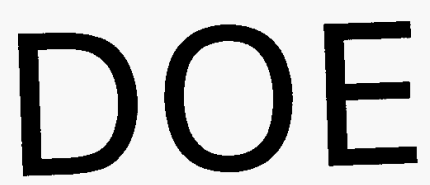

